\title{
Pain levels of patients undergoing ultrasound guided biopsies and associated factors: a cross-sectional study
}

\author{
(D)Mustafa Emre Akın \\ Yıldırım Beyazıt University, Yenimahalle Training and Research Hospital, Department of Radiology, Ankara, Turkey
}

Cite this article as: Akın ME. Pain levels of patients undergoing ultrasound guided biopsies and associated factors: a cross-sectional study. J Health Sci Med 2022; 5(1): 336-341.

\begin{abstract}
Aim: Patients may experience pain in minimally invasive biopsy procedures. It is important to evaluate the degree of pain and to know the factors that determine the level of pain felt by patients for adequate pain management. The aim of this study is to determine the pain levels felt by patients and socio-demographic and clinical factors associated with higher pain levels in breast and liver biopsy procedures.

Material and Method: In this cross-sectional observational study, patients who will undergo ultrasound-guided breast and liver biopsy procedures in the study center were invited to the study. The pain level was measured with the Visual Analogue Scale (VAS). Pain measurements above $45 \mathrm{~mm}$ were classified as moderate-to-high pain levels. The State-Trait Anxiety Scale was used to measure the anxiety levels of the patients and the radiologist. Sociodemographical (sex, age, education level, job, income) and clinical factors (biopsy site, duration, bosy mass index, anxiety level of the patient and the radiologist) that may be associated with the pain levels of the patients were analyzed.

Results: The sample consisted of 76 patients, 62 were female (81.6\%). The procedures consisted of 43 breast biopsies ( $56.6 \%)$, 33 liver biopsies (43.4\%). The median pain level measurement determined by the VAS is $20.0 \mathrm{~mm}$ (IQR: 9.3- 38.5). Most of the sample (59.2\%) stated that they felt mild pain. It was found that patients with higher anxiety levels and patients underwent liver biopsy had statistically significantly higher moderate-to-high pain levels than patients with lower anxiety (OR: 3.683 95\% CI: 1.159- 11.705, $\mathrm{p}=0.220$ ), patients who underwent breast biopsies (OR: 3.521, 95\% CI: 1.153- 10.752, p=0.023). A positive correlation was found between the level of pain and the level of anxiety $(r=0.267, p=0.020)$.

Conclusion: This study demonstrated that most ultrasound-guided biopsy procedures were performed with mild or no pain although higher patient anxiety levels were associated with higher pain levels during the procedures. Patients undergoing liver biopsy procedures had higher pain levels than breast biopsy procedures.
\end{abstract}

Keywords: Ultrasonography, biopsy, pain, breast, liver

\section{INTRODUCTION}

Minimally invasive biopsy procedures performed with radiological imaging are safe and provides comfort for patients with few side effects and short hospital stays. Therefore, ultrasound guided percutaneous breast and liver biopsies are preferred over open surgery and frequently performed (1-4). Nevertheless, it is known that patients experience distress and pain even in these minimally invasive radiological procedures (5).

Reducing the pain that the patients feel during minimally invasive biopsy procedures is important for many reasons. Firstly, it increases the patient's comfort. Additionally, pain and the fear of pain can be a reason for patients to delay the biopsy procedure. Patients who feel more pain during the procedure have been reported to have difficulties in compliance with follow-up and treatment (5), even hospitalization may be required due to the pain felt after biopsy procedures (6). For adequate pain management it is important to evaluate the degree of pain and to know the factors that affect the level of pain felt by patients during minimally invasive biopsy procedures.

It has been reported that patients who underwent ultrasound guided breast and liver biopsies feel some degree of pain (7-9). Pain sensation may be affected by many factors. Themost important associates of pain during ultrasound guided liver and breast biopsy procedures in the literature were anxiety $(7,10)$ and female sex $(11)$. As all of the studies in the literature included only one biopsy site, there is a gap in the literature in comparison of pain 
levels between breast and liver biopsy sites and studies aiming to report both clinical and socio-demographical associates of pain during biopsy procedures.

While it is necessary to know the pain levels and associated factors for breast and liver biopsy procedures, two most common minimally invasive biopsy procedures; the aim of this study is to determine the pain levels felt by patients and socio-demographic and clinical factors associated with higher pain levels in breast and liver biopsy procedures. It has been hypothesized that patients who undergo liver biopsy procedures would experience higher levels of pain than patients who undergo breast biopsy and also anxiety level of patients and the physician was associated with higher pain levels.

\section{MATERIAL AND METHOD}

All of the procedures followed were in accordance with the Helsinki Declaration. Ethical approval was obtained from the Institutional Review Board of Yildırım Beyazıt University Yenimahalle Trainig and Research Hospital for this study (Date: 13.10.2021, Decision No: E-2021$55)$.

The research was carried out in a cross-sectional and observational design. Patients who will undergo ultrasound guided breast and liver biopsies in the radiology department of the Yildırım Beyazit University Yenimahalle Trainnig and Research Hospital between October 15, 2021 and December 1, 2020 were invited to the study. Inclusion criteria were determined as being able to speak Turkish, being able to read and write, being over the 18 years of age. All patients were asked to sign written consent to participate in the study. Those with a previously diagnosed anxiety disorder or other psychiatric diseases, and those with a history of regular anxiolytic and analgesic use were excluded from the study.

All ultrasound guided biopsies performed in the Radiology Department of the study center are performed by the researcher radiologist. The patients who met the inclusion criteria and underwent ultrasound guided biopsy procedures were invited to the study during their appointments. Written consent and socio-demographic information forms were obtained from patients before starting the biopsy procedure. Socio-demographic form included information on patients' sex, age, education level, job and income to find out whether these factors were associated with pain.

All biopsy procedures were performed by the researcher, an experienced radiologist using aseptic technique and local anesthesia. Breast biopsy patients underwent ultrasound examination of the biopsy site with Toshiba Aplio 500 ultrasound machine (Toshiba Medical Systems, Otawara-Shi, Japan) using a $14 \mathrm{MHz}$ ultrasound probe. For local anesthesia, $2 \mathrm{ml}$ of $2 \%$ prilocaine without epinephrine was administered superficially followed by $10 \mathrm{ml}$ of $2 \%$ prilocaine without epinephrine around the lesion. After performing 2 $\mathrm{mm}$ length skin incision, under ultrasonographic guidance, $16 \mathrm{G}$ biopsy needle was used to obtain biopsy material. Liver biopsy patients, after lateral decubitus positioning, underwent ultrasound examination with Toshiba Aplio 500 ultrasound machine (Toshiba Medical Systems, Otawara-Shi, Japan) using a 3.5 MHz ultrasound probe. After superficial injection of $2 \mathrm{ml}$ of $2 \%$ prilocaine without epinephrine, $10 \mathrm{ml}$ of $2 \%$ prilocaine without epinephrine was administered to the deep soft tissues and around liver capsule. Following performing $2 \mathrm{~mm}$ length skin incision, through appropriate intercostal space, 16G biopsy needle was used to obtain biopsy material under ultrasonographic guidance. All liver biopsies were performed for parenchymal sampling.

After the wound dressing has ended, the participants were given pain and anxiety measures to fill. In addition, the researcher physician filled out the anxiety measure after each biopsy procedure and stated his momentary anxiety levels during that procedure. Biopsy duration was recorded by the researcher.

The Visual Analogue Scale (VAS) was used to measure the pain felt by the patient during biopsy. This scale is widely used to measure and follow-up pain levels in many studies over years $(12,13)$. This scale consists of a $100 \mathrm{~mm}$ horizontal line ruler with the feeling no pain at one end and unbearable pain at the other representing the minimum and maximum scores for pain. The ends of the scale were marked 'no pain' and 'most severe pain'. There were no intermediary markings on the scale. In this study, values between $0-4 \mathrm{~mm}$ were classified as "no pain", values between $5-44 \mathrm{~mm}$ as "mild pain", values between $45-74 \mathrm{~mm}$ as "moderate pain" and values between 75$100 \mathrm{~mm}$ as "severe pain" (11-14). The patients were asked to draw a vertical line representing their pain levels. The value was measured and recorded in milimeters by the researcher.

The State-Trait Anxiety Scale (STAI) was used to measure the anxiety levels of the patients and the radiologist. This scale was developed by Spielberger et al. in 1970, and is a Likert-type scale (four degrees varying from "none" to "completely") that measures state and trait anxiety levels with 20 questions separately (15). It consists of two subscales with 20 items each. The State Anxiety Scale aims to measure how the patient feels at the moment whereas the Trait Anxiety Scale aims to measure how the patient feels in general daily life as a self-report. The 
total score obtained from both scales varies between 20 and 80 . Higher scores indicate high anxiety levels while lower scores indicate low anxiety levels (15). Validity and reliability study of the scale in Turkey was performed (16). The measure that has been frequently used in previous studies on radiological biopsy procedures (17-20). In the study, both the patients state anxiety scores reflecting their anxiety levels during the biopsy procedure and their trait anxiety scores reflecting their general anxiety levels were investigated as associates of pain during the biopsy procedures. Additionally, if the state or trait anxiety levels of the patients were found to be high, the patient was consulted to psychiatry.

Numerical variables were expressed as mean and standard deviation (SD) if distributed normally; median and interquartile range (IQR $=25 \%-75 \%)$ values if not. The Shapiro-Wilk test was used to determine the distribution of data. Categorical variables were given as numbers and percentages. The differences of pain levels between two groups were tested with Student-t test if distributed normally, with Mann Whitney-U test if not. Pearson correlation analysis was used for investigating the relationship between pain and anxiety scores. To find the association between feeling moderate-to-severe pain during procedures with patients' clinical and sociodemographical variables Pearson Chi-Square test and Fisher Exact tests were used. The results were considered statistically significant when $\mathrm{p}<0.05$ and $95 \%$ confidence interval (CI). Statistical analyses were done using IBM SPSS 20.0 (SPSS Inc., Chicago, IL, USA) package program.

\section{RESULTS}

Out of 81 patients who underwent ultrasonographyguided biopsy during the study period; 3 patients with a previously diagnosed anxiety disorder and 2 patients with a history of regular analgesic use were excluded. Remaining 76 patients who provided informed consent comprised the sample of the study.

Sixty-two participants were female $(81.6 \%), 14$ were male $(18.4 \%)$. The mean age of the participants was 43.2 \pm 11.4 (Table 1). The youngest patient was 19 years old, and the oldest patient was 75 years old. Breast biopsy was performed for 43 patients (56.6\%), and liver biopsy was performed for 33 patients (43.4\%). Most of the sample had education less than 12 years $(78.9 \%)$ is and participants who had a job to sustain regular income constitute $30.3 \%$ of the sample. The mean biopsy time was $15.9 \pm 3.7$ minutes overall which was $17.3 \pm 3.8$ minutes in breast biopsies and $14.0 \pm 2.5$ minutes in liver biopsies, and the difference was statistically significant $(\mathrm{p}=0.047)$.
Table 1. Sociodemographic characteristics of the sample

\begin{tabular}{|c|c|}
\hline \multicolumn{2}{|c|}{ Sociodemographic characteristics $(\mathrm{N}=76)$} \\
\hline Age $\left(\right.$ mean $\left.\pm \mathrm{SD}^{*}\right)$ & $43.2 \pm 11.4$ \\
\hline \multicolumn{2}{|l|}{$\operatorname{Sex}(n, \%)$} \\
\hline Female & $62(81.6)$ \\
\hline Male & $14(18.4)$ \\
\hline \multicolumn{2}{|l|}{ Occupation (n, \%) } \\
\hline Housewife & $42(55.3)$ \\
\hline Working & $23(30.3)$ \\
\hline Unemployed & $4(5.3)$ \\
\hline Retired & $7(9.2)$ \\
\hline \multicolumn{2}{|c|}{ Educational background (n, \%) } \\
\hline Primary school & $25(32.9)$ \\
\hline Middle school & $18(23.7)$ \\
\hline High school & $17(22.4)$ \\
\hline University graduate & $16(21.1)$ \\
\hline
\end{tabular}

The median pain level measurement of the sample determined by the Visual Analogue Scale is $20.0 \mathrm{~mm}$ (25\% -75\%: 9.3-38.5). According to the VAS results, 14 patients $(18.4 \%)$ stated that they did not feel any pain, 45 patients $(59.2 \%)$ felt mild pain, 14 patients $(18.4 \%)$ felt moderate pain, and 2 patients (2.6\%) stated that they felt severe pain. The median pain level of the patients who underwent breast biopsy was $13.0 \mathrm{~mm}$ (IQR: 4-23); the median pain score of the patients who underwent liver biopsy was $28 \mathrm{~mm}$ (IQR: $18-49$ ) and the difference was statistically significant $(\mathrm{p}=0.001)$

The mean state anxiety level of the sample was $44.0 \pm 5.9$; trait anxiety level was $50.1 \pm 6.8$; the mean state anxiety level of the researcher who performed the biopsy procedure was $44.2 \pm 2.0$. The mean state anxiety level of researcher was $44.6 \pm 2.0$ in the breast biopsies which was higher than $43.6 \pm 1.7$ in the liver biopsies $(\mathrm{p}=0.020)$.

The relationships between the patient's feelings of moderate-to-high pain and the patient's sociodemographic and clinical characteristics were examined (Table 2). In these bivariate analyses, patients who reported higher anxiety levels felt significantly more pain than patients reported lower anxiety levels [Odd's ratio (OR): 3.683 95\% CI: 1.159-11.705, $\mathrm{p}=0.220$ ] and it was determined that the patients who underwent liver biopsy felt significantly more moderate-to-high levels of pain than those who had underwent breast biopsy (OR: 3.521, 95\% CI: 1.153-10.752, $\mathrm{p}=0.023$ ). A statistically significant positive correlation was found between the level of pain felt by the patient during biopsy and the level of anxiety $(r=0.267, p=0.020)$. 
Table 2. Bivariate analysis between the moderate-to-high level of pain levels and their sociodemographic and clinical characteristics

\begin{tabular}{|c|c|c|c|c|c|c|c|c|}
\hline \multirow{2}{*}{\multicolumn{2}{|c|}{ Sociodemographic characteristics }} & \multicolumn{2}{|c|}{ Rates } & \multicolumn{5}{|c|}{ Feeling moderate-to-high level of pain } \\
\hline & & \multirow{2}{*}{$\begin{array}{c}\text { n } \\
62 \\
14\end{array}$} & \multirow{2}{*}{$\begin{array}{c}\text { \% } \\
81.6 \\
18.4\end{array}$} & \multirow{2}{*}{$\begin{array}{c}\mathbf{n} \\
16 \\
2\end{array}$} & \multirow{2}{*}{$\begin{array}{c}\% \\
25,0 \\
16,7\end{array}$} & \multirow{2}{*}{$\begin{array}{c}\text { OR } \\
1.667\end{array}$} & \multirow{2}{*}{$\begin{array}{c}\mathbf{9 5} \% \mathbf{C I}^{*} \\
0.330-8.423\end{array}$} & \multirow{2}{*}{$\begin{array}{c}\mathbf{p} \\
0.720\end{array}$} \\
\hline Sex & $\begin{array}{l}\text { Female } \\
\text { Male }\end{array}$ & & & & & & & \\
\hline Age & $\begin{array}{l}>50 \\
\leq 49\end{array}$ & $\begin{array}{l}22 \\
54\end{array}$ & $\begin{array}{l}28.9 \\
71.1\end{array}$ & $\begin{array}{c}7 \\
11\end{array}$ & $\begin{array}{l}31,8 \\
20,4\end{array}$ & 1.824 & $0.598-5.564$ & 0.287 \\
\hline Education & $\begin{array}{l}>12 \text { years } \\
\leq 12 \text { years }\end{array}$ & $\begin{array}{l}16 \\
60\end{array}$ & $\begin{array}{l}21.1 \\
78.9\end{array}$ & $\begin{array}{c}3 \\
15\end{array}$ & $\begin{array}{l}18,8 \\
25,0\end{array}$ & 0.692 & $0.173-2.765$ & 0.748 \\
\hline Regular income & $\begin{array}{l}\text { Present } \\
\text { Absent }\end{array}$ & $\begin{array}{l}30 \\
46\end{array}$ & $\begin{array}{l}39.5 \\
60.5\end{array}$ & $\begin{array}{c}10 \\
8\end{array}$ & $\begin{array}{l}33,3 \\
17,4\end{array}$ & 2.375 & $0.810-6.965$ & 0.110 \\
\hline \multicolumn{9}{|l|}{ Clinical characteristics } \\
\hline Biopsy site & $\begin{array}{l}\text { Liver } \\
\text { Breast }\end{array}$ & $\begin{array}{l}33 \\
43\end{array}$ & $\begin{array}{l}43.4 \\
56.6\end{array}$ & $\begin{array}{c}12 \\
6\end{array}$ & $\begin{array}{l}36.4 \\
14.0\end{array}$ & 3.521 & $1.153-10.752$ & 0.023 \\
\hline Biopsy duration & $\begin{array}{l}\leq 15 \text { minutes } \\
>15 \text { minutes }\end{array}$ & $\begin{array}{l}40 \\
36\end{array}$ & $\begin{array}{l}52.6 \\
47.4\end{array}$ & $\begin{array}{c}12 \\
6\end{array}$ & $\begin{array}{l}30.0 \\
16.7\end{array}$ & 2.141 & $0.708-6.493$ & 0.172 \\
\hline $\mathrm{BMI}^{\star *}$ & $\begin{array}{l}>30 \\
\leq 30\end{array}$ & $\begin{array}{l}15 \\
61\end{array}$ & $\begin{array}{l}19.7 \\
80.3\end{array}$ & $\begin{array}{c}6 \\
12\end{array}$ & $\begin{array}{l}40.0 \\
19.7\end{array}$ & 2.722 & $0.811-9.135$ & 0.171 \\
\hline $\begin{array}{l}\text { State anxiety scale score } \\
\text { of the patients }\end{array}$ & $\begin{array}{l}>46 \\
\leq 45\end{array}$ & $\begin{array}{l}37 \\
39\end{array}$ & $\begin{array}{l}48.7 \\
51.3\end{array}$ & $\begin{array}{c}13 \\
5\end{array}$ & $\begin{array}{l}35.1 \\
12.8\end{array}$ & 3.683 & $1.159-11.705$ & 0.220 \\
\hline $\begin{array}{l}\text { Trait anxiety scale score } \\
\text { of the patients }\end{array}$ & $\begin{array}{l}>46 \\
\leq 45\end{array}$ & $\begin{array}{l}55 \\
21\end{array}$ & $\begin{array}{l}72.4 \\
27.6\end{array}$ & $\begin{array}{c}14 \\
4\end{array}$ & $\begin{array}{l}25.5 \\
19.0\end{array}$ & 1.451 & $0.417-5.049$ & 0.764 \\
\hline $\begin{array}{l}\text { State anxiety scale score } \\
\text { of the radiologist }\end{array}$ & $\begin{array}{l}>46 \\
\leq 45\end{array}$ & $\begin{array}{l}15 \\
61\end{array}$ & $\begin{array}{l}19.7 \\
80.3\end{array}$ & $\begin{array}{c}2 \\
16\end{array}$ & $\begin{array}{l}13.6 \\
26.2\end{array}$ & 0.433 & $0.880-2.131$ & 0.499 \\
\hline
\end{tabular}

\section{DISCUSSION}

In minimally invasive imaging-guided biopsy procedures, it is important to reduce the pain of patients and increase their comfort. In this study patients mostly felt minimal pain during ultrasound guided breast and liver biopsy procedures. The findings of the study showed that patients who underwent liver biopsy experienced a statistically significantly higher level of pain than those who underwent breast biopsy, and also that patients who were more anxious during biopsy felt higher levels of pain.

In this study, approximately $75 \%$ of the sample who underwent ultrasound guided biopsy stated that they did not feel any pain or felt mild pain. The median pain level of patients who underwent breast biopsy was $13.0 \mathrm{~mm}$ (IQR: 4-23), and it is consistent with the mild pain levels found in the breast biopsy study conducted by Soo et al. (7) on 136 women from the United States. The median pain level of the patients who underwent liver biopsy was $28 \mathrm{~mm}$ (IQR: 18-49). According to the literature, it was reported that patients felt moderate and severe pain in liver biopsies $(8,9,20)$. Low levels of pain reported in this study can be explained by the experience of the center, the application of local anesthesia during the procedure or the fact that the physician performing the biopsy was a researcher which may lead to patients' inclination to report lower pain levels.

In previous studies, the pain felt in ultrasound guided biopsies was found to be related to the age of the patient, low education level, being a woman, anxiety level, the number of biopsy procedures, physician-patient relationship, the experience of the person performing the biopsy, and the characteristics of the biopsy needle (7-9, 20-22). The reason for not finding a relationship between female gender and pain level in this study may be that all breast biopsies, which make up approximately half of the sample, were applied to women and breast biopsies were less painful or painless. In this study although the procedure duration of breast biopsies was found to be longer than liver biopsies and patients reported more anxiety in breast biopsies, it is shown that the pain levels felt by patients in liver biopsies were higher than pain levels reported in breast biopsies. In liver biopsies, passing through the peritoneum and liver capsule as well as skin, subcutaneous tissue, muscle tissue may explain the higher level of pain compared to breast biopsies (23). Another important finding is that patients who have higher anxiety levels during biopsy procedures experience higher levels of pain. This finding is compatible with many studies in the literature $(7,20,21)$. The absence of a significant relationship between body mass index and pain in this study is consistent with the literature (7). In addition, the relationship between the physician's spontaneous anxiety level during biopsy and the pain felt by the patient was investigated for the first time in this study, but a significant relationship was not found.

The findings of this study may help to guide clinical studies. It is important to reduce the parient's anxiety in ultrasound guided biopy procedures. It may be helpful to inform the patient before the biopsy and conduct an interview to reduce anxiety. The clinicians must consider recommending relaxation techniques and anxiolytics 
for reducing and managing anxiety levels of patients (24-26). Especially in patients undergoing liver biopsy, it is important to use effective analgesics in addition to reduce anxiety.

The study has some important limitations. The first is that the cross-sectional pattern limits cause and effect relationships between pain and anxiety. Conducting the study with a sample with low socioeconomic level and not including other biopsy sites other than breast and liver prevents the generalization of the findings to all ultrasound guided biopsy procedures. It should be noted that the pain levels during the biopsy procedures may be affected by many intrinsic and extrinsic factors which may not be controlled in this study. In addition, since the physician performing the biopsy procedure was also the researcher, there may be bias in patients' self-reports of their pain and anxiety levels.

\section{CONCLUSION}

Despite these limitations, there are strengths of this study. When investigating factors associated with pain which is a subjective feeling and is affected by many conditions; this study has taken comprehensive factors into consideration such as gender, education level, income level, many clinical characteristics and the physician's anxiety level during the biopsy procedure for the first time. In conclusion, the findings of this study show that most ultrasound guided biopsy procedures were performed painless or with mild pain, and that the biopsy site and the patient's anxiety levels were associated with the pain during the procedure. Using techniques that will reduce anxiety and use of effective analgesia even in minimally invasive biopsy procedures are important for pain management and patient comfort.

\section{ETHICAL DECLARATIONS}

Ethics Committee Approval: Ethical approval was obtained from the Institutional Review Board of Yildırım Beyazıt University Yenimahalle Trainig and Research Hospital for this study (Date: 13.10.2021, Decision No: E-2021-55).

Informed Consent: All patients signed the free and informed consent form.

Referee Evaluation Process: Externally peer-reviewed.

Conflict of Interest Statement: The authors have no conflicts of interest to declare.

Financial Disclosure: The authors declared that this study has received no financial support.

Author Contributions: All of the authors declare that they have all participated in the design, execution, and analysis of the paper and that they have approved the final version.

\section{REFERENCES}

1. Bick U, Trimboli RM, Athanasiou A, et al. Image-guided breast biopsy and localization: recommendations for information to women and referring physicians by the European Society of Breast Imaging. Insights Imag 2020; 11: 12.

2. American College of Radiology. ACR practice parameter for the performance of ultrasound-guided percutaneous breast interventional procedures. Available at: https: //www.acr.org/-/ media/ACR/Files/Practice-Parameters/US-GuidedBreast.pdf. 01.12.2021

3. Bedossa P, Patel K. Biopsy and noninvasive methods to assess progression of nonalcoholic fatty liver disease. Gastroenterology 2016; 150: 1811-22.e4.

4. Bruix J, Sherman M, Llovet JM, Beaugrand M, Lencioni R, Andrew K. Clinical management 4 of hepatocellular carcinoma. Conclusions of the Barcelona-2000 EASL Conference. 5 European Association for the Study of the Liver. J Hepatol 2001; 35: 421-30.

5. Flory N, Lang EV. Distress in the radiology waiting room. Radiology 2011; 260: 166-73.

6. Janes $\mathrm{CH}$, Lindor $\mathrm{KD}$. Outcome of patients hospitalized for complications after outpatient liver biopsy. Ann Intern Med 1993; 118: $96-8$

7. Soo AE, Shelby RA, Miller LS, et al. Predictors of pain experienced by women during percutaneous imaging-guided breast biopsies. J Am Coll Radiol 2014; 11: 709-16.

8. Eisenberg E, Konopniki M, Veitsman E, Kramskay R, Gaitini D, Baruch Y. Prevalence and characteristics of pain induced by percutaneous liver biopsy. Anesth Analg 2003; 96: 1392-6.

9. Tan KT, Rajan DK, Kachura JR, Hayeems E, Simons ME, Ho CS. Pain after percutaneous liver biopsy for diffuse hepatic disease: A randomized trial comparing subcostal and intercostal approaches. J Vasc Intervent Radiol 2005; 16: 1215-9.

10. Tekdogan U, Tuncel A, Nalcacioglu V, Kisa C, Aslan Y, Atan A. Is the pain level of patients affected by anxiety during transrectal prostate needle biopsy? Scand J Urol Nephrol 2008; 42: 24-8.

11.Drage N, Greenall C, Farnell DJ. Ultrasound-guided fine-needle aspiration cytology of lesions in the head and neck performed without local anaesthesia: an analysis of pain perception. Ultrasound 2018; 26: 222-8.

12. Price DD, McGrath PA, Rafii A, Buckingham B. The validation of visual analogue scales as ratio scale measures for chronic and experimental pain. Pain 1983; 17: 45-56.

13. Heller GZ, Manuguerra M, Chow R. How to analyze the Visual Analogue Scale: Myths, truths and clinical relevance. Scand J Pain 2016; 13: 67-75.

14. Jensen MP, Chen C, Brugger AM. Interpretation of visual analog scale ratings and change scores: a reanalysis of two clinical trials of postoperative pain. J Pain 2003; 4: 407-14.

15. Spielberger CD, Gorsuch RL, Lushene R, Vagg PR, Jakobs GA. Manual for the State-Trait Anxiety Inventory. Palo Alto CA: Consulting Psychologists Press Inc, 1983.

16. Ozguven IE. Stress and anxiety scales and sociometric, psychologic tests (in Turkish). Ankara: Yeni Dogus Matbaası, 1994: 321-324.

17. Haun M, Mainous RO, Looney SW. Effect of music on anxiety of women awaiting breast biopsy. Behav Med 2001; 27: 127-32.

18. Bugbee ME, Wellisch DK, Arnott IM, et al. Breast core-needle biopsy: clinical trial of relaxation technique versus medication versus no intervention for anxiety reduction. Radiology 2005; 234: 73-8.

19. Soo MS, Jarosz JA, Wren AA, et al. Imaging-guided core-needle breast biopsy: Impact of meditation and music interventions on patient anxiety, pain, and fatigue. J Am Coll Radiol 2016; 13: 52634.

20.Çakir Ö, Aksu C. Subcapsular local anesthesia approach in percutaneous liver biopsy: less pain, more comfort. Turk J Med Sci 2021; 51: 342-7. 
21.Zografos GC, Zagouri F, Sergentanis TN, Nonni A, Lymperopoulos N, Patsouris E. What parameters affect pain in core biopsy? Eur Radiol 2008; 18: 1144-5

22. Satchithananda K, Fernando RA, Ralleigh G, et al. An audit of pain/discomfort experienced during image-guided breast biopsy procedures. Breast J 2005; 11: 398-402.

23. Dotan Y, Carlebach M, Zuckerman E, Maruf M, Schiff E. Delayed bleeding after percutaneous liver biopsy. Eur J Case Rep Intern Med 2016; 3: 000359.

24.Sanansilp V, Dejarkom S, Deetayart S. Postoperative pain management and the risk factors in major operation: a baseline study of acute pain service, Siriraj Hospital. J Med Assoc Thai 2016; 99: 549-56.

25. Kumar M, Kumar J, Saxena I. The role of mental distraction on the pain response in healthy young Indian adults. J Clin Diagn Res 2012; 6: 1648-52.

26. Zeidan F, Gordon NS, Merchant J, Goolkasian P. The effects of brief mindfulness meditation training on experimentally induced pain. J Pain 2010; 11: 199-209. 